\title{
Have EU Derivative Policy Reforms since the 2008 Financial Crisis Been Designed Effectively?
}

\begin{tabular}{|r|l|}
\hline Journal: & Journal of Financial Regulation and Compliance \\
\hline Manuscript ID & JFRC-09-2020-0085.R1 \\
\hline Manuscript Type: & Original Article \\
\hline Keywords: & $\begin{array}{l}\text { derivatives, Game Theory, financial crisis, regulation, European Union, } \\
\text { European Market Infrastructure Regulation }\end{array}$ \\
\hline \multicolumn{2}{|l}{} \\
\hline
\end{tabular}

SCHOLARONE $^{\mathrm{m}}$
Manuscripts $^{\text {Manusion }}$ 


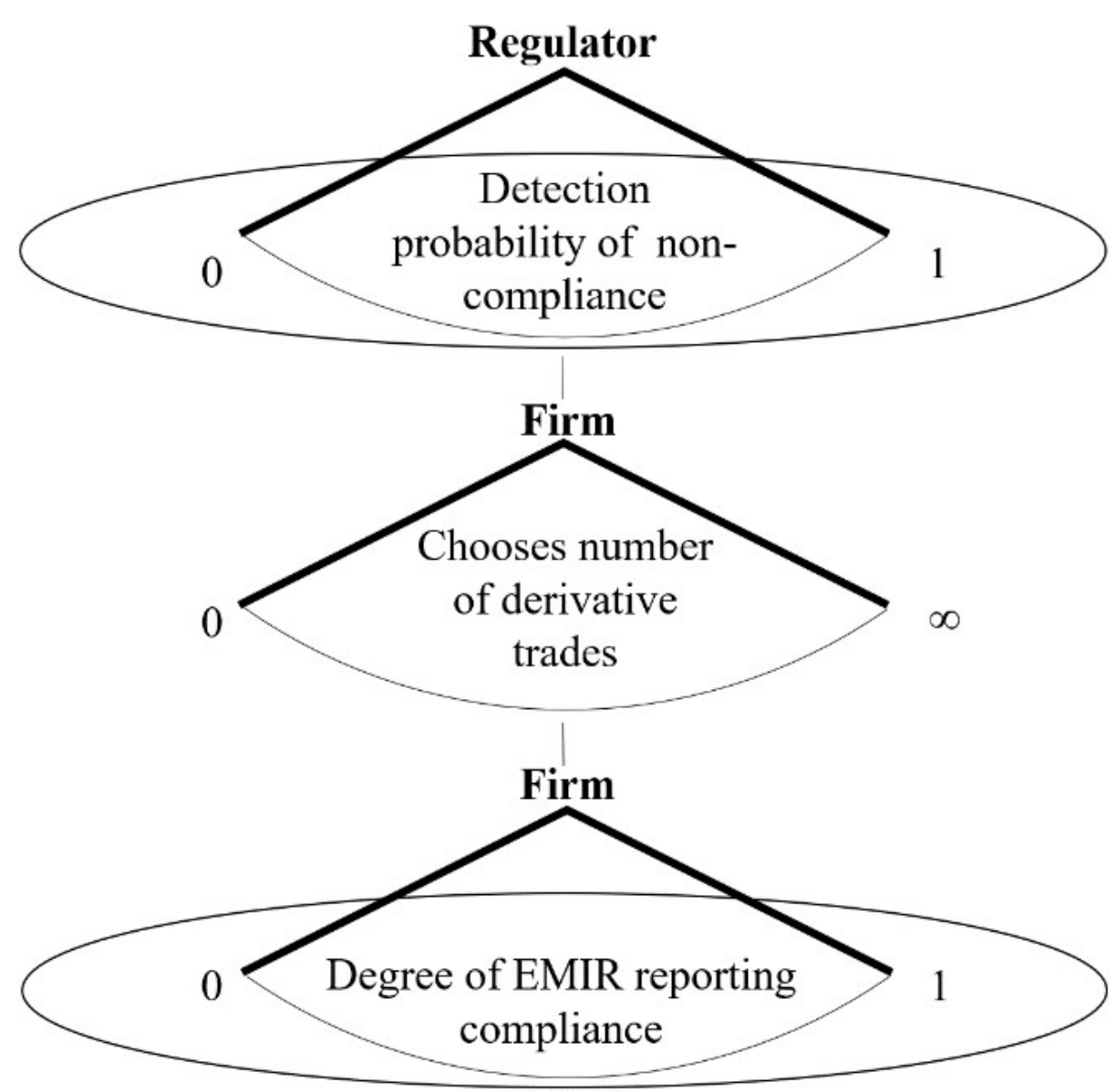

Figure 1: One-period, three stage EMIR reporting game $82 \times 75 \mathrm{~mm}(220 \times 220 \mathrm{DPI})$ 


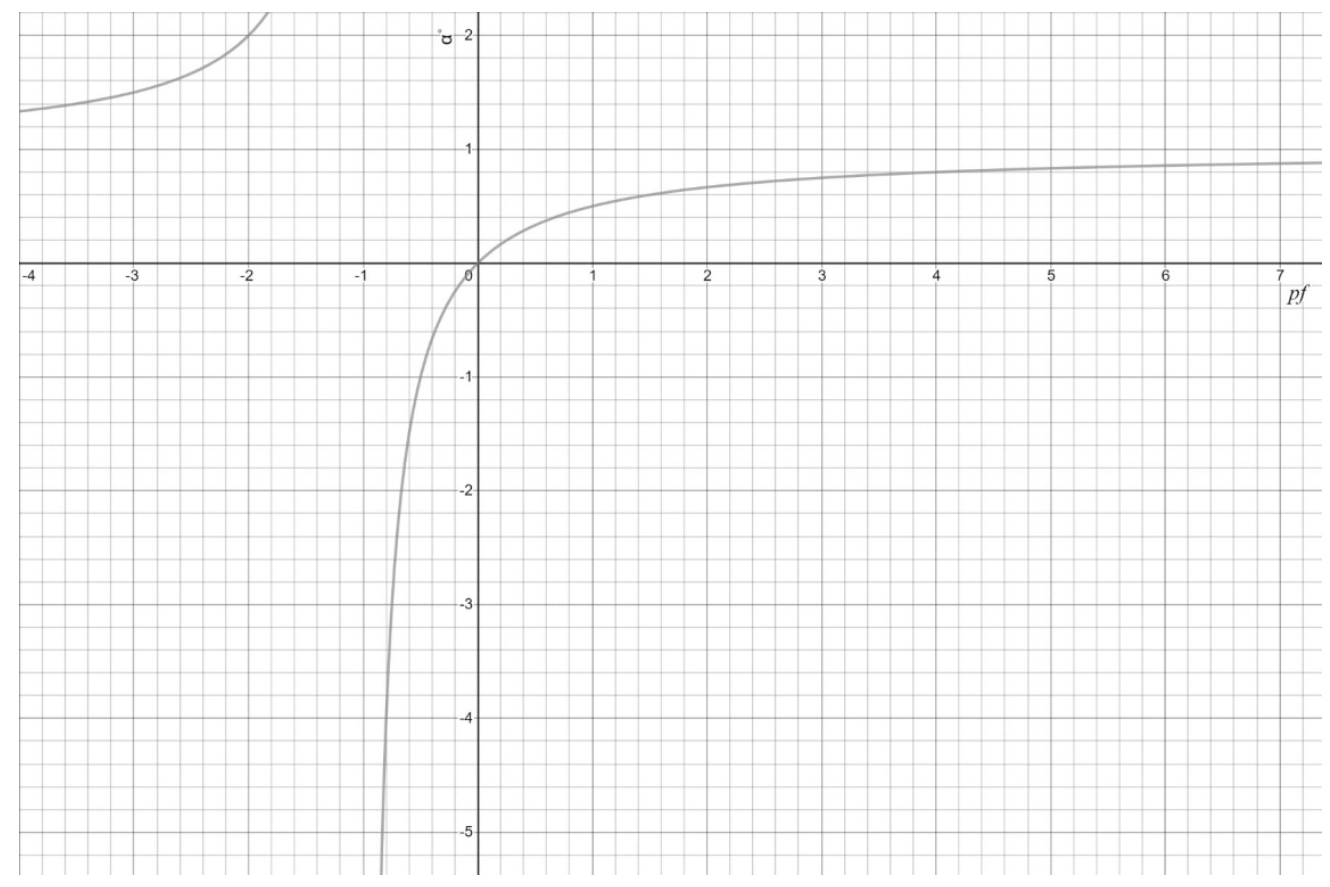

Figure 2: Effect of a change in the factor pf (x-axis) on optimal firm compliance (y-axis). $205 \times 136 \mathrm{~mm}(220 \times 220$ DPI $)$ 
1

2

3

4

5

6

7

8

9

10

11

12

13

14

15

16

17

18

19

20

21

22

23

24

25

26

27

28

29

30

31

32

33

34

35

36

37

38

39

40

41

42

43

44

45

46

47

48

49

50

51

52

53

54

55

56

57

58

59

60

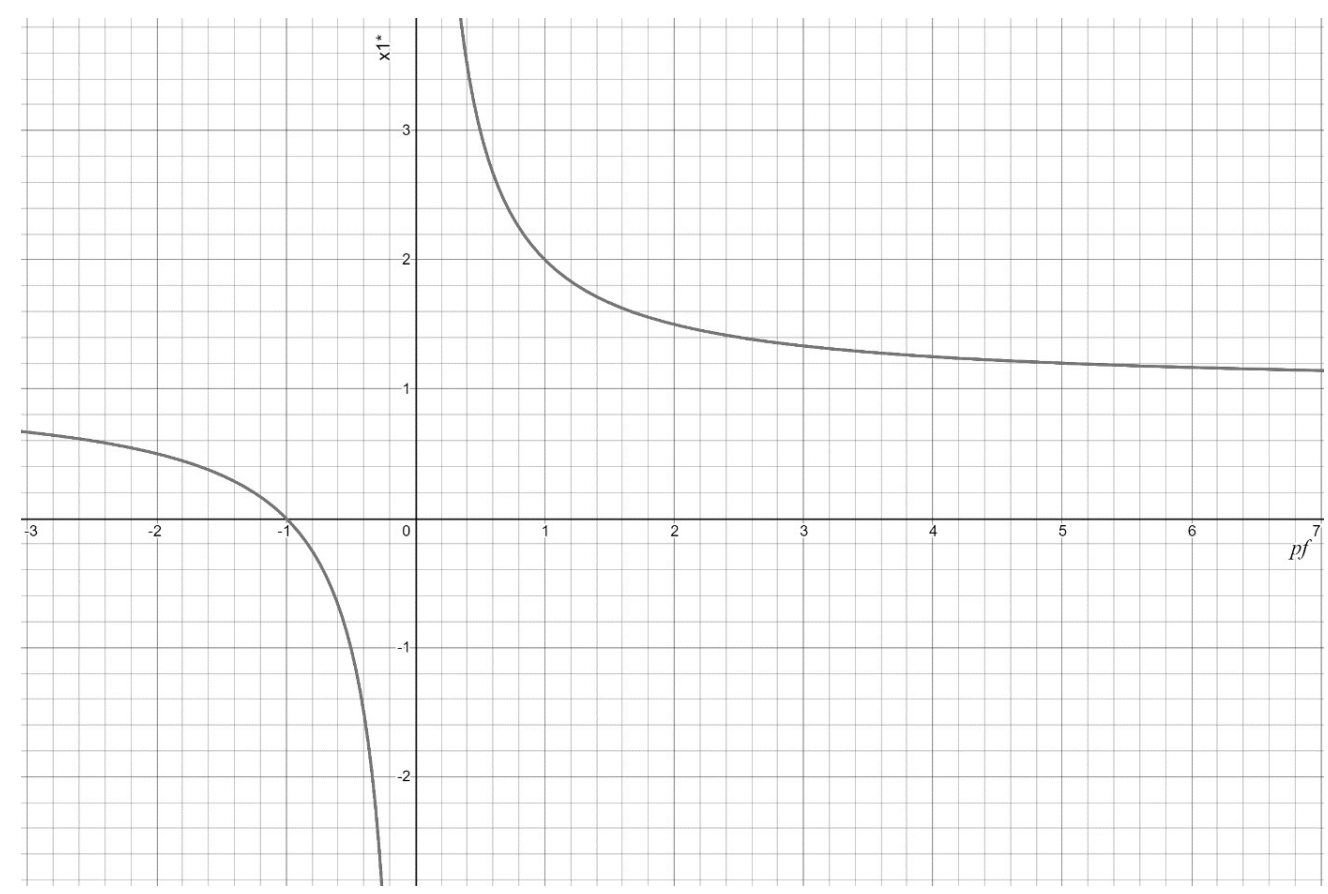

Figure 3: Effect of a change in the factor pf (x-axis) on optimal number of derivative trades (y-axis), ceteris paribus.

$160 \times 106 \mathrm{~mm}(220 \times 220 \mathrm{DPI})$ 


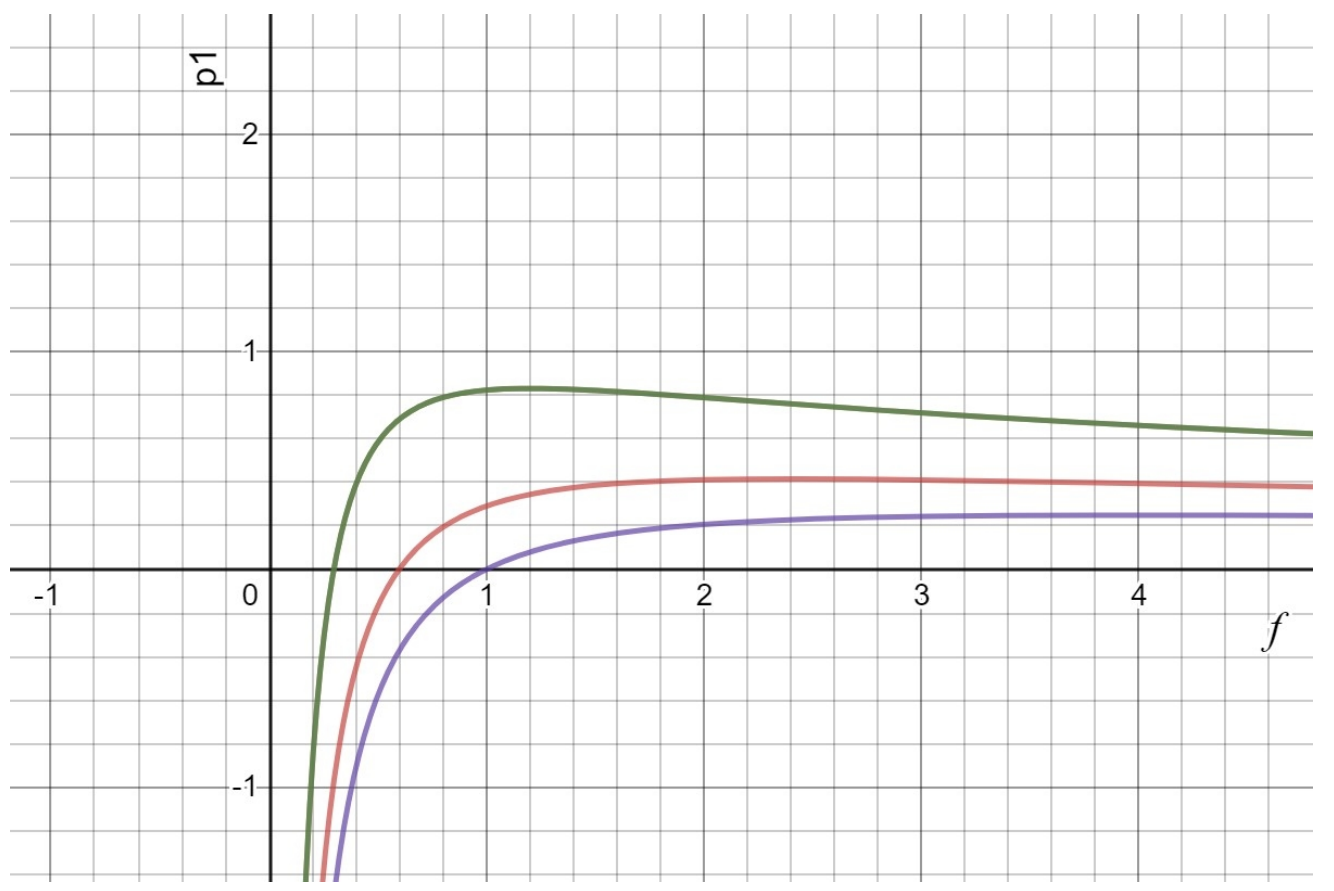

Figure 4: Effect of fine parameter on optimal detection probability with different detection costs $317 \times 211 \mathrm{~mm}(96 \times 96 \mathrm{DPI})$ 


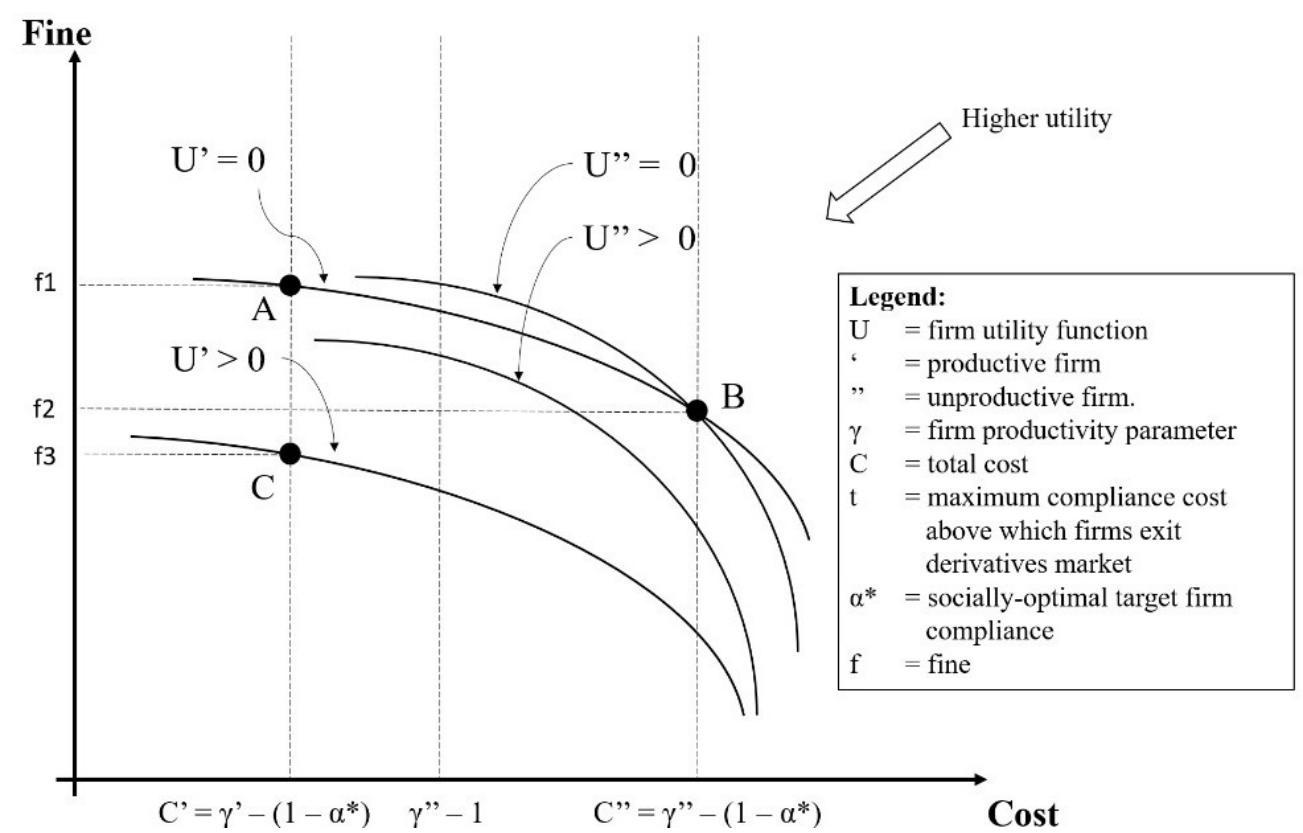

Figure 5: Conditions required to incentivise both firm types to comply optimally $260 \times 163 \mathrm{~mm}(96 \times 96 \mathrm{DPI})$ 


\title{
Have EU Derivative Policy Reforms since the 2008 Financial Crisis Been Designed Effectively? A Theoretical Analysis of EMIR Reporting Requirements
}

\begin{abstract}
Purpose:

In response to the 2008 financial crisis, the EU comprehensively restructured its derivative regulation. A key component of this new framework is a reporting obligation for every derivative trade. As the reporting requirement does not involve public disclosure of the information, existing academic analysis on reporting regulations to-date, which focuses on public disclosure, is limited in predicting the effectiveness of the reform. In this paper, I develop a theoretical model to assess whether the reform has been designed effectively based on the regulatory setup in the UK.
\end{abstract}

\section{Methodology:}

Framing the reporting regulation as a moral hazard problem with asymmetric information, this paper uses a game-theoretical approach to evaluate whether the new derivative reporting obligation effectively induces firm compliance. I also discuss potential extensions of the derivative reporting model, with particular emphasis on how the framework could account for heterogeneous firms and different regulatory tools.

\section{Findings:}

Based on the theoretical analysis, this paper finds that while firms are unlikely to comply fully with derivative reporting requirements, it is possible to induce relatively high firm compliance. Although this does not mean we are immune from another financial crisis, the derivative reporting requirements should equip EU regulators to monitor a more transparent and secure derivatives market.

\section{Originality:}

This paper provides a theoretical foundation for further study of post-crisis derivative reforms. In particular, the implications of the model point to an empirical strategy to test the accuracy of the model.

Keywords: Derivatives, Regulation, EU, European Market Infrastructure Regulation, EMIR, Financial Crisis, Game Theory.

Article classification: Research Paper 


\section{INTRODUCTION}

Derivatives are financial contracts whose value depend on an underlying asset. They are primarily used to reallocate risk exposures between economic agents. The derivatives market is divided into exchangetraded derivatives (ETDs) and over-the-counter (OTC) derivatives. ETDs are standardised contracts, traded through an intermediary counterparty that guarantees the trade if either counterparty defaults (Chui, 2012). OTC derivatives are agreed bilaterally and can be customised extensively. The size of the global OTC derivatives market was estimated to be \$640tn in 2019 (BIS, 2019), which is almost eight times global GDP (World Bank, 2019). In 2016, the size of the global ETD market was estimated to be around $10 \%$ of the global OTC derivatives market. Similarly, the European derivatives market is mainly OTC derivatives (European Commission, 2017).

While providing flexibility, OTC derivatives can create complex hidden networks of interdependence, obscuring the scale and location of risks (European Commission, 2012). According to the official EU report on the 2008 financial crisis, the lack of transparency in the OTC derivatives market is widely considered a significant contributor. The report explains that explosive growth of the highly complex OTC credit derivatives market, combined with the lax regulatory framework, led to widespread uncertainty as to both the size and nature of credit risks globally. As counterparty exposures to OTC derivative risks were unknown, liquidity markets dried up, further intensifying the effects of the collapse of the sub-prime housing market (De Larosiere et al., 2009). Before the 2008 financial crisis, the derivatives market was largely self-regulated, led by banks and industry bodies (Ayadi and Behr, 2009).

Following this EU report, the global G20 committed to improving the transparency and regulatory oversight of the OTC derivatives market. In Europe, this resulted in the European Market Infrastructure Regulation (EMIR). Under EMIR, there are three main requirements: clearing, margining and reporting. Standardised derivatives should be cleared through a central counterparty, which guarantees the trade if either counterparty defaults. Any non-cleared derivatives must be margined; the counterparties must exchange collateral as insurance against counterparty credit risk. Finally, both counterparties are required to report details of the trade to allow national authorities to monitor and reduce systemic risks associated with the derivatives market (European Commission, 2012).

To understand the chosen literature reviewed in the next section, it is important to explain the reporting requirement in more detail. For every agreement, amendment or expiry of a derivatives contract, both counterparties are required to report details who they are trading with and the nature of the trade. The dual nature of reporting is for data quality purposes and reduces the incentive to omit trades. Firms can choose to delegate the reporting obligation to the other counterparty or a third-party. The delegating firm remains responsible for the accuracy of the reports. There are over 100 fields in each report, although not all fields are applicable to each trade. Reports are submitted to a trade repository, where the data is aggregated and stored. The national regulator for each EU country can access the data to 
monitor the derivatives market and individual firm exposures (European Commission, 2012). In the UK for example, the financial services sector is regulated by the Financial Conduct Authority (FCA). Unlike most reporting regulations, the information reported is not disclosed publicly. This fundamentally changes the underlying regulatory mechanism and incentives. As of May 2020, the only UK enforcement case against a firm for EMIR reporting non-compliance was against Bank of America Merrill Lynch International (BAML) in 2017 for failing to report almost 70m trades. The FCA imposed a $£ 34.5 \mathrm{~m}$ fine (FCA, 2017a).

Given the effects of the 2008 financial crisis, which are partially due to the lack of transparency in the derivatives market, it is important that the chosen policy measures in response are effective in preventing similar crises. However, as I will explain in section 2.2, the effectiveness of disclosure policies in financial regulation is unclear. My research question is the following:

Does the regulatory mechanism underlying EMIR reporting requirements create sufficient economic incentives for firm compliance?

To answer this question, I will theoretically model EMIR reporting requirements. To motivate my research question and theoretical analysis, I will now discuss existing literature on EMIR reporting and disclosure policies as a regulatory tool.

\section{LITERATURE REVIEW}

\subsection{EMIR REPORTING}

There are a number of issues with EMIR reporting. Firstly, the dual nature of reporting has highlighted that the data quality is low. ESMA (2018) estimated that 14\% of reports could not be paired with the counterparty report, indicating that basic information was inconsistent between reports. Pérez-Duarte and Skrzypczynski (2018) found worse pairing rates, with almost 25\% of trade reports being unpaired. A Freedom of Information Act revealed that only 40\% of EMIR trade reports matched (Wilkes, 2019), suggesting that the quality of information submitted was poor, even if the reports could be paired. Given these paring and matching rates, it is unlikely that the data can currently be used to accurately assess systemic financial risk.

Rousová et al. (2015) emphasises logistical issues with EMIR reporting. The counterparties could report the trade to different entities, hampering the reconciliation of reports. Furthermore, the lack of harmonisation of reporting requirements across non-EU countries makes aggregation of international 
data difficult, narrowing the scope to assess the global systemic risk of derivative trading (van Lelyveld, 2017).

Unlike for other requirements introduced under EMIR, there are no obvious economic incentives for firms to accurately report all their derivative trades. For certain commodity derivatives, firms reporting under EMIR are exempt from reporting exemptions for overlapping regulations such as REMIT (European Commission, 2014a). However, this does not apply to MiFIR reporting for example, another large-scale reporting requirement for financial instruments including derivatives (European Commission, 2014b). It is conceivable that firms may use their EMIR reports for documentation purposes. Overall, EMIR reporting is primarily a pure cost for firms (FIA, 2019).

In contrast, the Financial Stability Board (2018) finds significant economic incentives for firms to participate in clearing. For example, capital obtained through clearing is given preferential treatment, due to the resulting lower risk exposures for the firm. Clearing also allows for various risk management techniques, such as netting, that reduce counterparty credit risk exposures and therefore a financial firm's capital requirements (FSB, 2018). The economic case for the margin requirements under EMIR is less straightforward. However, given that margining is reserved for non-standard trades that cannot cleared easily, costly margin requirements may be beneficial for financial stability by encouraging firms to trade in standardised derivatives, which can be cleared. Therefore, economic incentives to margin are less important than incentives to clear. Additionally, unlike for EMIR reporting requirements, the clearing and margining requirements do not apply to firms trading in volumes below certain thresholds (European Commission, 2012). As argued by Levine and Macey (2017) for the US-equivalent of EMIR, these thresholds and differential treatment of cleared and non-cleared derivatives act as a Pigouvian tax on systemically important US firms. The social cost of creating systemic risk may not be factored into firms' business models. By varying the compliance costs according to business activity risk and firm size, firms are incentivised to avoid creating concentrated risk. However, EMIR reporting requirements apply equally to both ETDs and OTC derivatives and apply to all firms, contrary to the Pigouvian tax argument.

EMIR is a relatively new policy. It is unclear whether the issues with EMIR reporting requirements can be ironed out, or whether it is fundamentally flawed. As noted by Claessens and Kodres (2014) in their paper on issues with the global regulatory response to the 2008 financial crisis, there is a gap in the academic literature on the effectiveness of post-crisis regulations and requirements. While academic literature is silent on EMIR reporting, the effectiveness of mandatory disclosure policies in other areas of financial regulation are widely discussed. To assess whether literature on other disclosure policies could be applied to EMIR reporting, we now look into the academic study of disclosure policies. 


\subsection{MANDATORY DISCLOSURE POLICIES}

Mandatory disclosure policies are a common regulatory technique, where private or public institutions are required to reveal information to satisfy a clear regulatory objective (Weil et al., 2006). Proponents argue that they allow market participants to make informed decisions at low cost (Ben-Shahar and Schneider, 2014).

Weil et al. (2006) provide a framework to assess the effectiveness of a regulatory disclosure policy. They argue that mandatory disclosure policies are only effective if the resulting information allows both the information users and disclosers to significantly improve their choices at an acceptable cost. More recent papers have largely agreed with this criteria, for example Mitchell (2011), who cautions that "transparency can best be viewed as a "weak" cause of behavioural change."

Cross-country empirical studies have shown that corporate financial reporting requirements are associated with greater capital market development (Porta et al., 2006), higher market liquidity (Christensen et al., 2016) and lower cost of capital (Hail and Leuz, 2006). However, Leuz and Wysocki (2016) explain that causal effects of disclosure policies are hard to estimate because they are often a response to a major event. For this reason, it is difficult to distinguish between the market reactions to the event and the effect of the disclosure policy itself.

The lack of empirical evidence conclusively supporting disclosure policies is echoed by Ben-Shahar and Schneider (2014). They question whether disclosure policies carry any significant benefits, as the resulting information is often complex and thus difficult to understand. Additionally, they argue that due to the vast number of existing disclosure policies, even if a disclosure policy was effective in isolation, the policies become ineffective when aggregated. The authors acknowledge that this argument is difficult to show empirically, but suggest that the resulting net effect would prove most disclosure policies unjustifiable.

In relation to financial markets, Shen (2011) finds that while incomplete disclosure has been pinpointed as the root cause of the mis-selling of minibonds by Lehman Brothers in Hong Kong, full disclosure would still have been insufficient due to the complexity of the underlying product. The paper suggests that disclosure policies should only be used to supplement rigorous protective regulation. Avgouleas (2009) argues that while the pre-crisis disclosure framework contributed significantly to the 2008 crisis, disclosure policies are not necessarily fundamentally flawed. In particular, he suggests that disclosure policies have clear benefits in some cases, such as market abuse regulation and making capital market more democratic.

Academic papers have theoretically modelled the effects of disclosure policies. Guttentag (2007) develops a model of the relationship between disclosure policies and social welfare. Goldstein and Yang (2017) model the key mechanisms through which disclosure policies affect financial markets, 
highlighting several trade-offs needed to assess the optimal level of information disclosure. Hermalin and Weisbach (2012) present a principal-agent model that demonstrates how, even assuming there is no direct cost of a disclosure policy, the optimal disclosure level may be bounded. Kanto and Schadewitz (1997) model the relationship between information and quality in interim reports and the subsequent stock market reaction. Cohen and Santhakumar (2007) present a theoretical model of mandatory disclosure policies and bargaining power in environmental regulation. Alvarez and Barlevy (2015) model how mandatory disclosure policies can limit financial contagion, concluding that there is only a role for mandatory disclosure when there is sufficient interdependence across banks.

While these models formalise elements of EMIR reporting that are relevant to assessing its effectiveness, there are underlying assumptions in each of the models that diminish their applicability to EMIR. Guttentag (2007), Goldstein and Yang (2017), Kanto and Schadewitz (1997) and Cohen and Santhakumar (2007) assume that the information is disclosed publicly. As explained previously, in the case of EMIR reporting, the information is not disclosed publicly but directly to the regulator. Additionally, models such as the environmental disclosure model by Cohen and Santhakumar (2007) assume that the negative externality, in their case pollution, is easily quantifiable. This is not the case with financial stability, limiting the applicability of such models to the case of EMIR reporting. The models presented by Hermalin and Weisbach (2012) and Cohen and Santhakumar (2007) assume that the economic agents can influence the extent of disclosures. In the case of EMIR, it would be more realistic to assume that the disclosure policy is mandated exogenously, as the regulatory requirements are already in place. These bargaining models typically model the relationship between senior management and the shareholders, instead of the firm and the government. The model presented by Alvarez and Barlevy (2015) models how disclosure policies can mitigate information asymmetries between a bank and its investors. They incorporate a different punishment mechanism than in the firmregulator scenario, limiting the applicability of the model.

A lack of unifying theory of mandatory disclosure mechanisms is echoed by Beyer et al. (2010). They explain that this is because the benefit of mandatory disclosure policies is based on how the welfare effects of each stakeholder are valued. They also caution that more transparency can be detrimental in some principal-agent models if more information facilitates collusion between agents. The authors acknowledge that in some cases no disclosure can be better than a one-tiered approach. For this reason, they advocate further research into of how one-size-fits-all reporting standards impact differing firms. Leuz and Wysocki (2016) also see scope for further theoretical research to identify potential regulatory effects of disclosure policies. They argue this would allow for carefully designed empirical studies to estimate the causal effects of disclosure policies.

In short, current theory and empirical evidence on disclosure policies cannot be directly applied to the case of EMIR reporting, due to a different underlying mechanism through which the policy hopes to 
achieve transparency. The overview above highlights the gap in academic literature of non-public disclosure policies. To accurately assess the effectiveness of the design of EMIR reporting, we need a new model of the relationship between the reporting firm and the regulator that reflects the setup of the regulation.

\section{Methodology}

In this paper, I use game theory to model the actions of the regulator and the reporting firm within the legislative framework set out under EMIR. This allows us to understand the optimal decisions of each agent subject to the optimal actions of the other agent. Game theory is a particularly useful method in this setting because both agents are self-interested and rational.

To model the firm-regulator EMIR reporting game, we divide the decisions made by each agent into three stages. This allows us to determine how much information each agent knows when they make a decision, which affects any constraints on their optimal decision. We distinguish at each stage whether the decision made is visible to the other agent. We use backward induction to solve for the optimal actions of each agent, which is the standard method for solving sequential games (Osborne, 2009). Backward induction starts at the final decision in a game, working backwards to deduce the optimal decision of each agent subject to the decisions made so far.

Within each stage of the game, we use constrained optimisation to maximise the utility of each agent. This allows us to incorporate any restriction on decision-making based on the EMIR reporting framework to account for any limitations from the actions of the other agent. As derivative reporting by firms and the monitoring of derivatives reporting by the regulator are costly for the respective agent, we can maximise the utility of each agent by minimising their costs. We follow the standard cost minimisation methodology which is explained in more detail in Pemberton and Rau (2015).

The subsequent analysis is set out as follows. In section 4.1, I explain the setup of the model. In section 4.2, I solve the EMIR reporting model step-by-step using backward induction and constrained optimisation. Section 5 discusses the implications of the model; section 6 extends the model to heterogeneous firms and section 7 concludes.

\section{ANALYSIS}

\subsection{OVERVIEW}

We will base the EMIR reporting model on the regulatory setup in the UK. The regulatory objectives of the FCA, the UK financial services regulator, are public and clear. They would like to "protect consumers", "protect financial markets" and "promote competition" (FCA, 2019a). A more transparent derivatives market contributes to these goals by increasing financial stability through better oversight 
Figure 1 illustrates the one-period, three stage EMIR reporting game, which we will solve using backward induction. Note that the circles symbolise an information asymmetry at that stage. Starting in the final stage, the firm chooses how much they would like to comply with EMIR reporting requirements, which is hidden from the regulator. Based on this, the firm chooses how many derivative trades to undertake, which is visible to the regulator. The regulator forms an expectation of firm compliance, in part based on the disclosed number of trades and chooses a

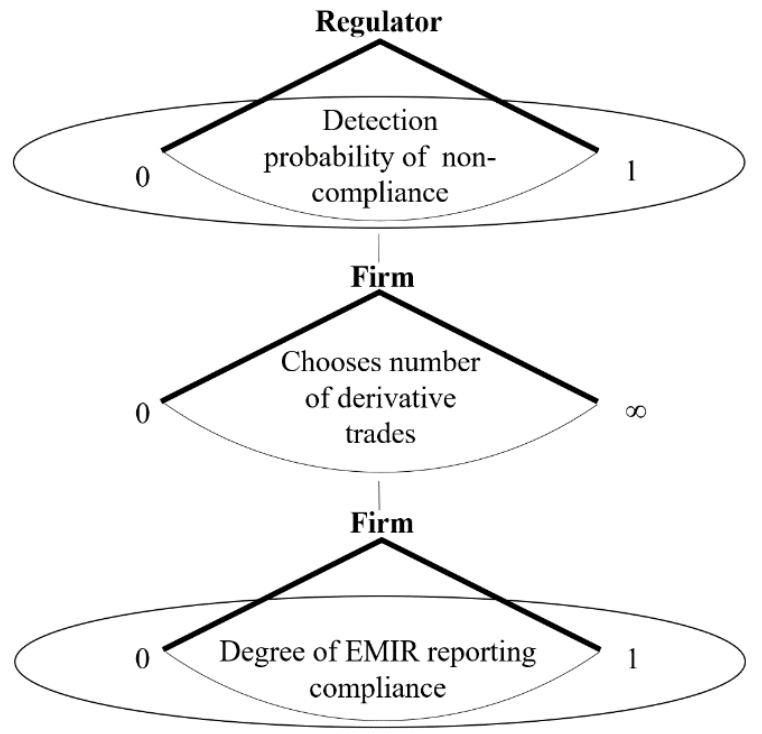

Figure 1: One-period, three stage EMIR reporting game detection probability for any non-compliance, which is associated with a fine.

As the reporting requirements are the same for all types of derivatives, we will not distinguish between derivative types. Based on the BAML non-compliance enforcement case, we assume that the regulatory tool available is a fine and associated non-compliance detection probability. In UK financial regulation, fines for regulatory breaches are determined based on the principles outlined in the FCA handbook (FCA, 2020). Fines are also not the only regulatory tool available to the regulator. While a firm may be able to roughly estimate how the regulator will punish any non-compliance, there is significant leeway for the regulator to take action they deem appropriate to maintain financial stability (FCA, 2020). For ease of analysis, we assume that firms are risk-neutral. As in the figure above, we assume that the regulator observes how many trades the firms undertakes. As both counterparties are required to report, it is likely that the regulator observes at least one side of the trade, even if the quality of the report is low. Additionally, the regulator could use information on the frequency of derivative trading from other 
regulations, such as MiFIR for example, which focuses on identifying market abuse (European Commission, 2014b).

\subsection{EMIR REPORTING MODEL}

We look at the setting of one firm and one regulator. In section 4.2.1, the firm chooses to what extent they would like to comply with EMIR reporting requirements, but this is hidden from the regulator. Based on this, in section 4.2.2, the firm chooses the number of derivative trades it would like to undertake. In section 4.2.3, the regulator determines how much to prioritise EMIR reporting by choosing the non-compliance detection probability, which is hidden from the firm. Based on this game setup, we can formalise this principal-agent problem mathematically.

\subsubsection{STAGE 3: EMIR REPORTING COMPLIANCE}

The firm would like to choose a level of EMIR reporting compliance, $\alpha \in[0,1]$, to minimise their costs. Their cost function has two inputs: derivative trading, $\mathrm{x}_{1}$, and all other business activities, $\mathrm{x}_{2}$. We denote the input price of all other business activities as $\mathrm{w}_{2}$. We assume that EMIR reporting is the only cost to derivative trading for firms. In a first stage, we assume the number of derivatives trades a firm undertakes is exogenous. Finally, we assume that the cost of compliance increases exponentially as the firm approaches full compliance. While primarily a technical assumption to ensure that the cost function is twice-differentiable, it may be reasonable given the complexity of derivatives and the extent of the reporting details required under EMIR. As the firm approaches full compliance, the costs associated with designing IT systems that accurately assess and report each trade for example may increase significantly. For simplicity, we assume this results in the input cost of compliance, $\alpha$, being squared. Based on these assumptions, the firm has the following cost function, $C(\alpha)$ :

$$
C(\alpha)=\alpha^{2} x_{1}+w_{2} x_{2}
$$

The probability of being fined for any non-compliance, $p \in[0,1]$, is unknown to the firm. However, we assume they can approximate the relationship between non-compliance, number of trades affected and the resulting fine. For this, we introduce a constant fine parameter $\mathrm{f}>0$. Once again, to ensure twicedifferentiability, we assume the firm expects higher non-compliance to be punished exponentially more severely. Given the cumulative risks of non-compliance to maintaining a transparent derivatives market, this seems to be a reasonable assumption in line with punishment guidelines set-out in the FCA handbook (FCA, 2020). Based on this, the firm approximates the fine mechanism as follows:

$$
F(\alpha)=(1-\alpha)^{2} f x_{1}
$$


Using $C(\alpha)$ and $F(\alpha)$, we can construct the firm's expected disutility function, $G(\alpha)$ :

$$
\begin{aligned}
G(\alpha) & =(1-p) C(\alpha)+p[C(\alpha)+F(\alpha)] \\
& =(1-p)\left[\alpha^{2} x_{1}+w_{2} x_{2}\right]+p\left[\alpha^{2} x_{1}+w_{2} x_{2}+(1-\alpha)^{2} f x_{1}\right] \\
& =\alpha^{2} x_{1}+w_{2} x_{2}+p(1-\alpha)^{2} f x_{1}
\end{aligned}
$$

The firm would like to choose the value for $\alpha$ that minimises their expected disutility. To find this optimal compliance level, $\alpha^{\circ}$, we differentiate $G(\alpha)$ with respect to $\alpha$ and set $G^{\prime}(\alpha)$ equal to zero:

$$
\begin{aligned}
G^{\prime}(\alpha) & =2 \alpha x_{1}-2 p(1-\alpha) f x_{1} & \mid \text { Set } G^{\prime}(\alpha)=0 \\
2 \alpha x_{1} & =2 p(1-\alpha) f x_{1} & \mid \div 2 x_{1} \\
\alpha & =p f-\alpha p f & \mid+\alpha p f \\
\alpha^{\circ} & =\frac{p f}{1+p f} &
\end{aligned}
$$

The optimal firm compliance is positively associated with the extent of the fine, $f$, and the noncompliance detection probability, $\mathrm{p}$. As $\mathrm{f}$ and $\mathrm{p}$ are non-negative, in this model full compliance $\left(\alpha^{\circ}=1\right)$ is only optimal if the fine is infinitely large. This is illustrated graphically in figure 2.

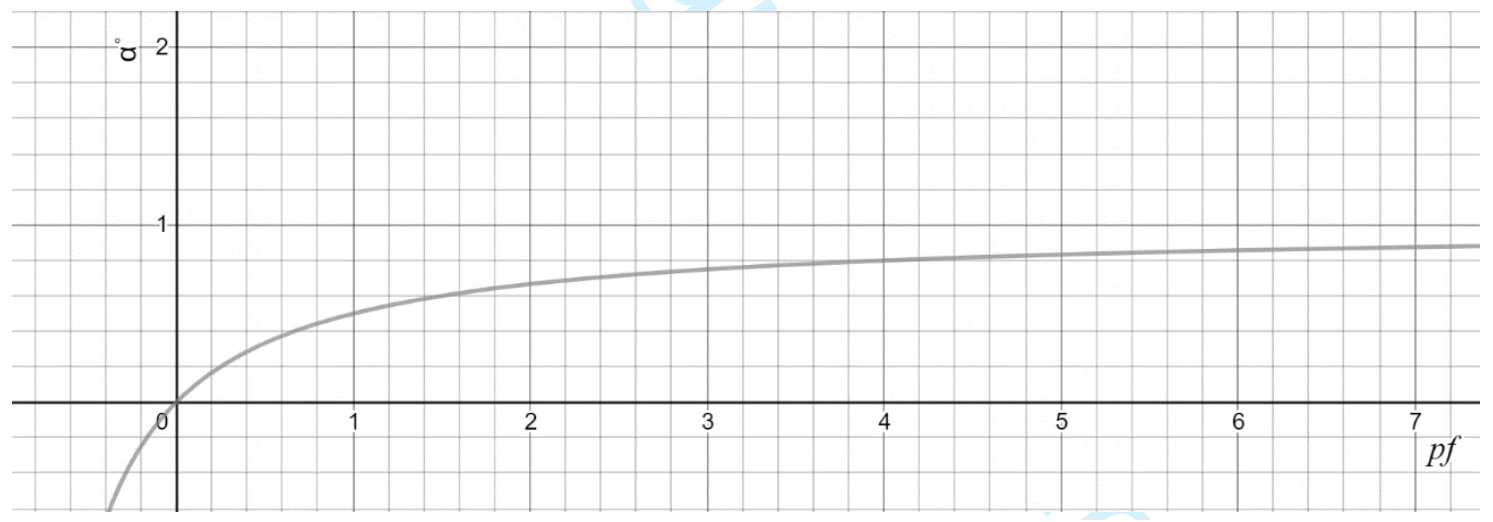

Figure 2: Effect of a change in the factor pf (x-axis) on optimal firm compliance (y-axis).

It is important to note that in this setup, optimal firm compliance is independent of the number of trades the firm undertakes. This is largely due to the chosen functional forms, and may not hold in the real world. It is conceivable that the non-compliance detection probability $\mathrm{p}$ is dependent on the number of derivative trades. In UK financial regulation for example, smaller firms are grouped together based on their business model, whereas larger financial firms are monitored individually by dedicated teams (FCA, 2019b). Therefore, there is most likely a link between firm size, the number of derivatives they trade in and how closely their derivative reporting is scrutinised.

To verify that equation (9) is a minimum for the expected disutility function $G(\alpha)$, we calculate the second derivative: 


$$
G^{\prime \prime}(\alpha)=2 x_{1}+2 p f x_{1}
$$

As the number of derivative trades $\mathrm{x}_{1}$, the non-compliance detection probability $\mathrm{p}$ and the fine parameter f are strictly non-negative, the second derivative is positive, meaning $G^{\prime}(\alpha)=0$ is a minimum.

\subsubsection{STAGE 2: NUMBER OF DERVIATIVE TRADES}

We now endogenize the number of trades. To do this, we plug the optimal compliance level, $\alpha^{\circ}$, from equation (9) back into $G(\alpha)$ :

$$
G(\alpha)=\alpha^{\circ} x_{1}+w_{2} x_{2}+p\left(1-\alpha^{\circ}\right)^{2} f x_{1}
$$

By factorising equation (10), the problem becomes a standard cost minimisation question with cost function $\mathrm{C}\left(\mathrm{x}_{1}, \mathrm{x}_{2}\right)$ :

$$
C\left(x_{1}, x_{2}\right)=\hat{\mathrm{w}}_{1} x_{1}+w_{2} x_{2} \quad \text { where } \hat{\mathrm{w}}_{1} \equiv \alpha^{\circ}+p\left(1-\alpha^{\circ}\right)^{2} f
$$

For ease of derivation, we assume that the firm has a Cobb-Douglas production function, where $\mathrm{q}$ is equal to output and $\beta \in[0,1]$ is a constant. Output is difficult to define in financial services. In this case, output is the cumulation of all of a financial firms' business activities.

$$
\min _{x_{1} x_{2}} \hat{w}_{1} x_{1}+w_{2} x_{2} \text { subject to } x_{1}{ }^{\beta} x_{2}^{1-\beta}=q
$$

Aa detailed by Pemberton and Rau, (2015), we can solve this cost minimisation problem using Lagrange's method of undetermined multipliers. Let $\mathrm{L}\left(\mathrm{x}_{1}, \mathrm{x}_{2}, \lambda\right)$ be the Lagrangian function, where $\lambda$ is the Lagrange multiplier:

$$
L\left(x_{1}, x_{2}, \lambda\right)=\hat{\mathrm{w}}_{1} x_{1}+w_{2} x_{2}-\lambda\left[x_{1}{ }^{\beta} x_{2}{ }^{1-\beta}-q\right]
$$

By differentiating $\mathrm{L}$ with respect to $\mathrm{x}_{1}, \mathrm{x}_{2}$ and $\lambda$, we obtain the conditions for a critical point:

$$
\begin{aligned}
& \frac{\partial L}{\partial x_{1}}=\hat{\mathrm{w}}_{1}-\lambda \beta x_{1}{ }^{\beta-1}{x_{2}}^{1-\beta} \\
& \frac{\partial L}{\partial x_{2}}=\mathrm{w}_{2}-\lambda(1-\beta) x_{1}{ }^{\beta} x_{2}{ }^{-\beta} \\
& \frac{\partial L}{\partial \lambda}=x_{1}{ }^{\beta} x_{2}{ }^{1-\beta}-q
\end{aligned}
$$

Setting each equal to zero and rearranging:

$$
\begin{aligned}
& \hat{\mathrm{w}}_{1}=\lambda \beta x_{1}{ }^{\beta-1}{x_{2}}^{1-\beta} \\
& \mathrm{w}_{2}=\lambda(1-\beta) x_{1}{ }^{\beta} x_{2}{ }^{-\beta}
\end{aligned}
$$




$$
x_{1}^{\beta} x_{2}^{1-\beta}=q
$$

As the isoquants of a Cobb-Douglas function are negatively sloped and convex, the first-order conditions (equations (11), (12) and (13)) are sufficient for a minimum (Pemberton and Rau, 2015).

To solve for cost-minimising $\mathrm{x}_{1}$, divide (11) by (12) and simplify:

$$
\frac{(11)}{(12)}: \frac{\hat{w}_{1}}{w_{2}}=\frac{\lambda \beta x_{1}{ }^{\beta-1} x_{2}{ }^{1-\beta}}{\lambda(1-\beta) x_{1}{ }^{\beta} x_{2}{ }^{-\beta}}=\frac{\beta x_{2}}{(1-\beta) x_{1}}
$$

Rearranging for $\mathrm{x}_{1}$, subbing into (13) and then solving for cost-minimising $\mathrm{x}_{2}$ :

$$
\begin{aligned}
x_{1} & =\frac{w_{2} \beta}{\hat{\mathrm{w}}_{1}(1-\beta)} x_{2} \\
q & =\left[\frac{w_{2} \quad \beta}{\hat{\mathrm{w}}_{1}(1-\beta)} x_{2}\right]^{\beta} x_{2}{ }^{1-\beta} \\
q & =\left[\frac{w_{2} \quad \beta}{\hat{\mathrm{w}}_{1}(1-\beta)}\right]^{\beta} x_{2}^{\beta} x_{2}{ }^{1-\beta} \\
x_{2}{ }^{*} & =\frac{q}{\left[\frac{w_{2}}{\hat{\mathrm{w}}_{1}(1-\beta)}\right]^{\beta}}
\end{aligned}
$$

We plug (15) back into (14) to solve for cost-minimising $\mathrm{x}_{1}$ :

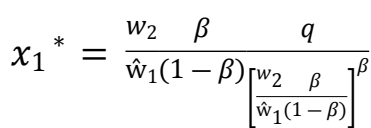

$$
\begin{aligned}
& =q\left[\frac{w_{2}}{\hat{\mathrm{w}}_{1}(1-\beta)}\right]^{1-\beta}
\end{aligned}
$$

Substituting $\hat{\mathrm{w}}_{1}$ for its definition (equation (10)):

$$
x_{1}^{*}=q\left[\frac{w_{2}}{\alpha^{0}+p f\left(1-\alpha^{\circ}\right)^{2}(1-\beta)}\right]^{1-\beta}
$$

At optimal firm compliance $\alpha^{\circ}$ from equation (9):

$$
x_{1}^{*}=q\left[\frac{w_{2}}{\left(\frac{p f}{1+p f}\right)^{2}+p f\left(1-\frac{p f}{1+p f}\right)^{2}(1-\beta)}\right]^{1-\beta}
$$

The optimal number of trades increases with the cost of alternative business activities, $\mathrm{w}_{2}$, and with total output of the firm, q. Additionally, the optimal number of trades is infinite if the expected punishment pf is zero. Ceteris paribus, the change in the optimal number of trades decreases rapidly with a higher expected punishment pf, although, as illustrated in figure 3 , there are decreasing effects of a higher punishment on the optimal number of trades. As the expected punishment is a proxy for the 
cost of derivative trading, this result would be particularly important if the cost of reporting varied across derivatives with different associated systemic risk. As in US derivative regulation and other elements of EMIR, the EMIR reporting requirement would act as a Pigouvian tax on higher risk derivatives. Different reporting requirements across derivative types would not necessarily enhance the quality of reports, but would provide an incentive for the market to trade in historically safer derivatives.

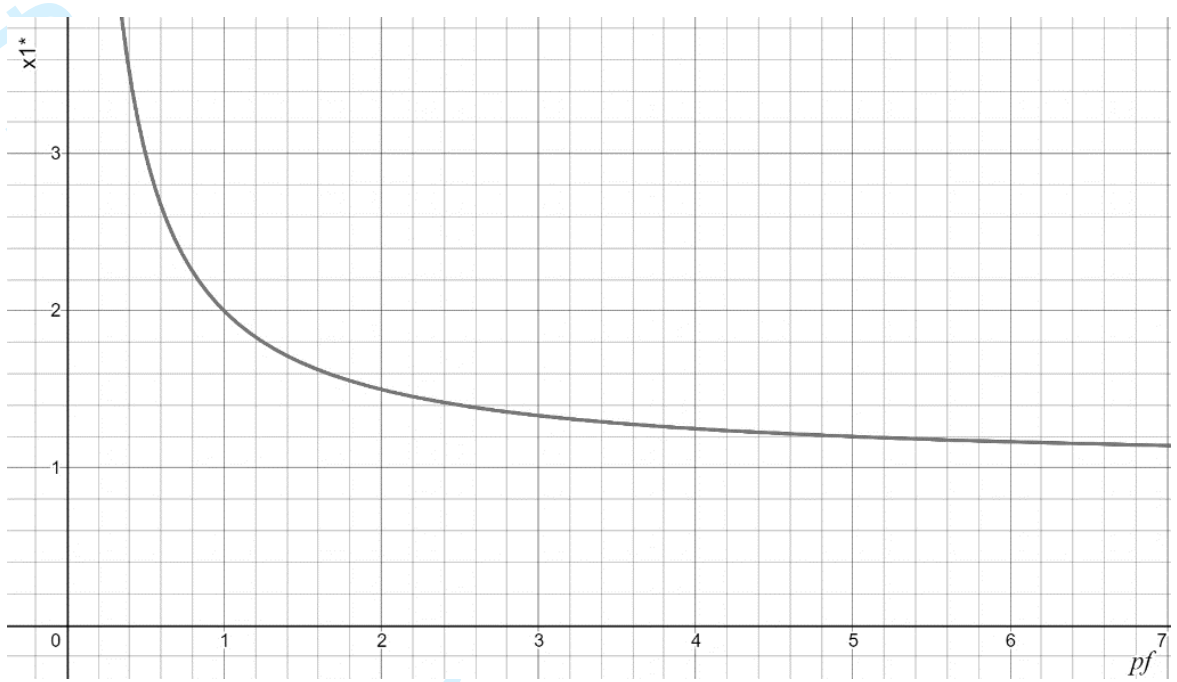

Figure 3: Effect of a change in the factor pf (x-axis) on optimal number of derivative trades (y-axis), ceteris paribus.

\subsubsection{STAGE 1: NON-COMPLIANCE DETECTION PROBABILITY}

We assume the regulator forms an expectation of compliance based on the above analysis of the firm's problem. At first glance, this may seem to violate the imperfect information assumption. However, we have assumed that the number of trades is not hidden from the regulator. Therefore, based on the number of trades, the regulator can infer some information about the firm's cost minimisation decision. This is similar to an assumption made in Crew and Parker (2006)'s information revelation model in which the regulator can use their knowledge of the firm's disutility of effort function to infer the level of effort provided by the firm. This model is considered in section 6 . We can also justify the assumption using insights from game theory. Even with information asymmetries, if the game structure is known, players can still know what the other players will do in equilibrium. Specifically, according to Osborne (2009), to find a Nash equilibrium in an imperfect information setting, we need two assumptions. Firstly, we assume that each player is acting optimally at all times given their beliefs of the other player's actions. Secondly, we assume that each player's beliefs about the other player's actions are correct in equilibrium. In other words, if the objectives of each of the players are clear, we can find an equilibrium where each player is responding optimally to their beliefs of the actions of the other player's actions. It is important to note that this assumption does not rule out the regulator's expected firm compliance being wrong. Otherwise, we would be modelling a perfect information setting. 
To determine the non-compliance detection probability $\mathrm{p}$ that maximises social welfare, we use a simple social welfare loss function, H(p), based on Becker and Landes (1974). We assume there is an exogenous target compliance level, $\alpha^{*} \in[0,1]$. The social benefit of EMIR reporting is the target compliance level less any firm non-compliance based on optimal firm compliance from equation (9) and the cost of non-compliance detection.

We assume the cost of detection is a linear function scaled by a cost parameter c:

$$
\begin{aligned}
H(p) & =\alpha^{*}-\left(1-\alpha^{\circ}\right)-c p \\
& =\alpha^{*}-\left(1-\frac{p f}{1+p f}\right)-c p
\end{aligned}
$$

The regulator maximises social welfare with respect to the detection probability, $\mathrm{p}$ :

$$
\begin{aligned}
H^{\prime}(p) & =\frac{f}{1+p f}-\frac{p f^{2}}{(1+p f)^{2}}-c \\
& =\frac{f}{(1+p f)^{2}}-c
\end{aligned}
$$

To find the maximum, set $\mathrm{H}^{\prime}(\mathrm{p})$ equal to zero and rearrange:

$$
\begin{aligned}
\frac{f}{(1+p f)^{2}} & =c \\
\frac{f}{c} & =(1+p f)^{2} \\
\frac{f}{c} & =1+2 p f+p^{2} f^{2} \rightarrow f^{2} p^{2}+2 p f+\left[1-\frac{f}{c}\right]=0
\end{aligned}
$$

Using the quadratic formula:

$$
\begin{aligned}
& p=\frac{-2 f \pm \sqrt{(2 f)^{2}-4 f^{2}\left[1-\frac{f}{c}\right]}}{2 f^{2}} \\
& p_{1}=\frac{-2 f+\sqrt{(2 f)^{2}-4 f^{2}\left[1-\frac{f}{c}\right]}}{2 f^{2}}=\frac{-2 f+\frac{2 f^{\frac{3}{2}}}{\sqrt{c}}}{2 f^{2}}=\frac{\frac{f^{\frac{3}{2}}}{\sqrt{c}}-f}{f^{2}}=\frac{f^{\frac{3}{2}}}{\sqrt{c} f^{2}}-\frac{1}{f} \\
& p_{1}=\frac{1}{\sqrt{c f}}-\frac{1}{f} \\
& p_{2}=\frac{-2 f-\sqrt{(2 f)^{2}-4 f^{2}\left[1-\frac{f}{c}\right]}}{2 f^{2}}=\frac{-2 f-\frac{2 f^{3 / 2}}{\sqrt{c}}}{2 f^{2}}=\frac{-\frac{f^{3 / 2}}{\sqrt{c}}-f}{f^{2}}=-\frac{f^{3 / 2}}{\sqrt{c} f^{2}}-\frac{1}{f}=-\frac{1}{\sqrt{c f}}-\frac{1}{f}
\end{aligned}
$$

As probabilities are constrained between zero and one and the cost and fine parameters are nonnegative, $\mathrm{p}_{2}$ is not a feasible solution to our problem. To ensure $\mathrm{p}_{1}$ is the critical point that maximises the social welfare function $\mathrm{H}(\mathrm{p})$, we look at the critical point at the second derivative $\mathrm{H}^{\prime \prime}(\mathrm{p})$ : 


$$
\begin{aligned}
& H^{\prime \prime}(p)=-\frac{2 f^{2}}{(1+p f)^{3}} \\
& \rightarrow \text { At } p_{1}:-\frac{2 f^{2}}{\left(1+\left[\frac{1}{\sqrt{c f}}-\frac{1}{f}\right] f\right)^{3}}=-\frac{2 f^{2}}{\left(\frac{f}{\sqrt{c f}}\right)^{3}}=-\frac{2 f^{2}(c f)^{\frac{9}{2}}}{f^{3}}=-2 c^{\frac{3}{2}} f^{\frac{1}{2}}<0 \text { for all } c, f>0
\end{aligned}
$$

The second derivative demonstrates that we have found an appropriate critical point for our analysis, where the social welfare function is concave. The socially-optimal non-compliance detection probability, (17), depends negatively on the cost of detection. The optimal detection probability initially increases with the fine parameter $\mathrm{f}$, before decreasing after a certain point. As illustrated in figure 4 , this turning point, marked black, depends on the cost parameter. The graph also shows how a higher cost parameter significantly reduces the optimal non-compliance detection probability for all values of the fine in this model. If the cost of detection is too high, the model implies that, to promote higher social welfare, the regulator should allocate its limited resources elsewhere.

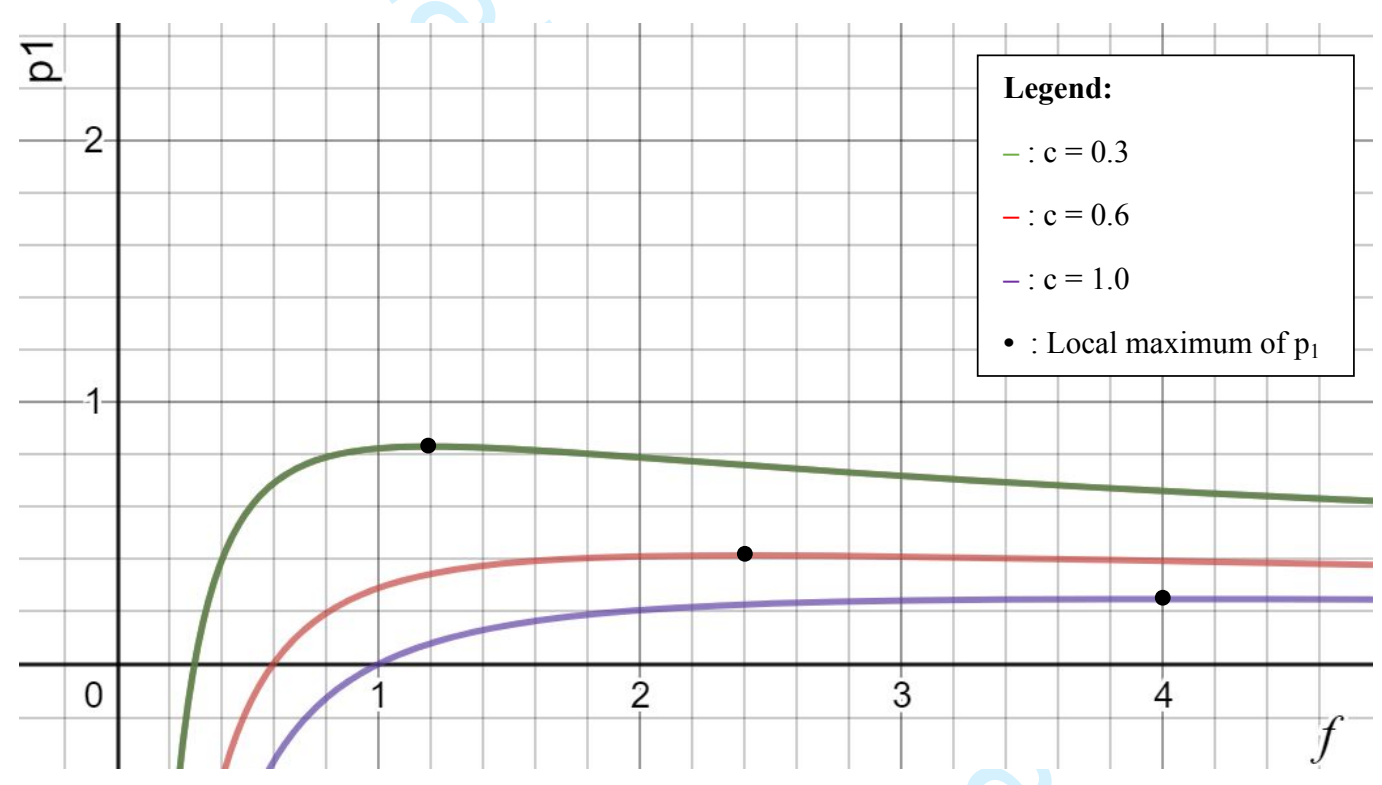

Figure 4: Effect of fine parameter on optimal detection probability with different detection costs

The social welfare function, $\mathrm{H}(\mathrm{p})$, has a local maximum at:

$$
\begin{aligned}
H\left(p_{1}\right) & =\alpha^{*}-\left(1-\frac{p_{1} f}{1+p_{1} f}\right)-c p_{1} \\
& =\alpha^{*}-\left(1-\frac{\left(\frac{1}{\sqrt{c f}}-\frac{1}{f}\right) f}{1+\left(\frac{1}{\sqrt{c f}}-\frac{1}{f}\right) f}\right)-c\left(\frac{1}{\sqrt{c f}}-\frac{1}{f}\right) \\
& =\alpha^{*}-\left(1-\frac{\frac{\sqrt{f}}{\sqrt{c}}-1}{\frac{\sqrt{f}}{\sqrt{c}}}\right)-\frac{\sqrt{c}}{\sqrt{f}}+\frac{c}{f} \\
& =\alpha^{*}+\frac{c}{f}-\frac{2 \sqrt{c}}{\sqrt{f}}
\end{aligned}
$$


Based on this, the effects of higher fines and higher detection costs on social welfare are ambiguous. The precise effects depend on how they are scaled in both relative and absolute terms.

We can summarise the key steps from the above analysis:

1. The firm chooses their optimal compliance level subject to detection and fine parameters

$$
\alpha^{\circ}=\frac{p f}{1+p f}
$$

2. Based on this, the firm chooses the number of derivative trades to undertake in order to minimise their costs:

$$
x_{1} *=q\left[\frac{w_{2}}{\left(\frac{p f}{1+p f}\right)^{2}+p\left(1-\frac{p f}{1+p f}\right)^{2} f^{(1-\beta)}}\right]^{1-\beta}
$$

3. The regulator chooses a non-compliance detection probability to maximise social welfare, subject to their beliefs of the firm's optimal compliance choice:

$$
p_{1}=\frac{1}{\sqrt{c f}}-\frac{1}{f}
$$

\section{DISCUSSION}

This discussion is divided into three stages: implications of the analysis, limitations of the EMIR reporting model and possible extensions of the model to address these limitations. In section 6, I will use the example of heterogeneous firms and using different regulatory tools to illustrate how these extensions could be done.

There are four main implications of above analysis. Firstly, in the model, firms will never provide full compliance unless they believe the fine parameter $\mathrm{f}$ is infinite. Therefore, an expectation of full compliance from the regulation may be unrealistic, particularly with such a new, complex and regularly amended and updated regulation.

Secondly, equation (16), showing the firm's optimal number of trades, suggests that getting firms to comply in the first place is the main challenge. All subsequent increases in firm compliance have a smaller effect on the firm's business decision in terms of the optimal number of derivative trades. Therefore, while a socially-optimal level of firm compliance around one may be unattainable, the model suggests that it is possible to induce firms to a relatively high extent.

Thirdly, as long as the firm believes they are likely to be caught if they do not comply, it is optimal to comply. If the objectives of the regulator are clear and in line with the socially-optimal EMIR reporting target compliance, EMIR reporting requirements are designed to induce a non-zero compliance level 
incentivised by the regulator to be as high as possible. Based on the modelling above, EMIR reporting requirements should enhance the transparency of the derivatives market.

Finally, equation (16) points to a possible empirical strategy for detecting non-compliant firms. Specifically, the equation suggests that firms that undertake a large number of derivative trades are either very efficient in complying with EMIR reporting requirements at low cost or do not comply with the requirements and therefore can trade in derivatives cheaply. Identifying firms that are particularly active in derivatives markets, while controlling for firm efficiency would be a possible empirical strategy for evaluating EMIR reporting compliance. While this may be a feasible strategy for academic study of the effectiveness of EMIR reporting, it may not be a good strategy for the regulator to detect non-compliance, as firms could change their behaviour in response to avoid detection. Aside from using EMIR reporting data, another empirical approach would be analysing the EMIR reporting breaches. Whenever a firm identifies an error in their reporting, they are obligated to report the breach to the regulator (European Commission, 2012). For example, reported breaches could be used as a proxy for firm non-compliance.

I have identified seven main limitations of the EMIR reporting model:

- The model is a one-period, three-stage game that does not account for learning by the firm or the regulator.

- Risk aversion and irrationality of either agent are not incorporated in the model. While risk neutrality and rational agents are standard assumptions in many economic models, given the information sets and resulting uncertainty, they may not be reasonable assumptions for EMIR reporting.

- Socially-optimal target compliance, $\alpha^{*}$, is determined exogenously. While the above analysis suggests that an excessive expectation of firm compliance may be unrealistic, the model does not provide insight into how to determine a socially-optimal target level of firm compliance.

- The model does not differentiate between different derivatives types. As highlighted in the introduction, all derivatives are subject to the EMIR reporting requirement. However, if the model is extended to endogenize socially-optimal target compliance, the differences in riskiness by derivative types would be important to determine the welfare effects of non-compliance for each derivative type.

- The one-firm one-regulator setup may miss general equilibrium effects when scaling up the problem to a many-firms one-regulator problem.

- In this model, fines are the only regulatory tool available to the regulator. In practice, the FCA has many possibilities, such as suspending firms from undertaking certain activities or deauthorising individuals or firms from participating in regulated financial markets (FCA, 2017b). 
- The model does not account for heterogeneity in the firm efficiency or size.

Extending the EMIR reporting model to multiple time periods would allow agents to base their actions on past beliefs and signals. With multiple time periods, we could model reputational effects to create a more representative picture of how agents behave in reality. There are many models of reputation in imperfect information games to base an extension of the EMIR reporting model on, which can be extended to include discounting over time and many agents (Cripps, 2006). I would expect incorporating reputational effects to increase compliance over time as long as the regulator consistently signals that maintaining a transparent derivatives market is a regulatory priority.

Given the extent of uncertainty in the EMIR reporting model, it could be important to incorporate risk aversion. Tax evasion principal-agent models with risk averse agents, first analysed by Allingham and Sandmo (1972) and Yitzhaki (1974), model a comparable imperfect information setting to EMIR reporting. These model and subsequent extensions by Gordon (1989), who includes reputational effects, and by Bernasconi (1998), who focuses specifically on the relationship between risk aversion and tax evasion, for example, provide a useful starting point for including risk aversion in the imperfect information model. Given that EMIR reporting contributes to financial stability, I would expect risk aversion to increase compliance, both to avoid being fined and to contribute to a safer derivatives market as a market participant.

Ideas from behavioural economics may also provide interesting extensions to the EMIR reporting model. It may not be that firms rationally choose not to comply to a certain degree. Instead, it is possible that the same heuristics and biases that appear when agents make decisions under uncertainty, first presented by Tversky and Kahneman (1974), may play a role in explaining issues with EMIR reporting compliance. One possible extension would be using models of references dependence to analyse the impact of the BAML non-compliance fine (FCA, 2017a) on the regulator's reputation and consequential firm compliance decisions. The application of behavioural economic concepts to firms is not widely explored in academic literature, although Armstrong and Huck (2010) provide insight into why the idea of an irrational firm may be viable and relevant for economic modelling. Extending regulatory models to include concepts from behavioural economics may be a promising avenue for further research.

To endogenize the socially-optimal target compliance level, we would need either theoretically model or empirically quantify the benefits and costs of EMIR reporting to society. It is likely that the burden of EMIR reporting costs trickles down to consumers in the form of higher prices for financial services. Therefore, the welfare costs are largely composed of the compliance costs and any Pareto distortions arising from how these costs fall on consumers. There may also be political implications if the regulator were to advocate a socially-optimal target compliance level below full compliance. As mentioned previously, the benefit of disclosure policies to society, in this case preventing a financial crisis, is difficult to quantify (Beyer et al., 2010), (Leuz \& Wysocki, 2016). Assessing the socially-optimal target 
level of EMIR reporting compliance would require careful weighting of the welfare benefits for many different stakeholders.

Extending the EMIR reporting model to account for different derivative types would involve expanding the production function to more than two inputs. Exemplary models for this type of extension include Liu et al. (2012) and Kiser (2004). As highlighted in the discussion of equation (16) in section 4.2.1, I would expect that differentiating between derivatives would provide support for varying reporting requirements to act as a Pigouvian tax to maximise social welfare.

To account for potential general equilibrium effects, the EMIR reporting model could be extended to many firms as illustrated by the general equilibrium models by Lehmus (2011) and Reiter (2009). Modelling financial stability as a public good may also be an interesting perspective when scaling up the EMIR reporting model to many market participants. This would incorporate incentives to 'free-ride' on the financial stability provided high-quality reporting by other market participants, a potential effect the current one-firm-one-regulator model omits.

Incorporating all regulatory tools available to the regulator would likely overcomplicate the EMIR reporting model. One extension could be allowing the fine parameter to be negative, i.e. to subsidise firms that provide high compliance. Accurately determining the value of the subsidy would be subject to the same issue of unobserved EMIR reporting quality. Xepapadeas (1991) models combining fines and subsidies to reduce carbon emissions under imperfect information. Sappington and Sibley (1988) model optimal subsidy design when, as with EMIR reporting, the firms cost structure is unknown. Crew and Parker (2006) illustrate how to design contracts to induce optimal regulatory compliance when the compliance costs are subsidised.

Given the diversity of firms in the financial services industry, it is important to understand how different firms could be incentivised to comply with EMIR reporting. In addition to incorporating subsidies, Crew and Parker (2006)'s information revelation model how to model firms with different efficiency levels. In essence, we are extending a moral hazard problem to include adverse selection. As Crew and Parker model incentive design under imperfect information, I originally considered basing the EMIR reporting model on their information revelation model. However, there are intricate assumptions in their model that do not apply to EMIR reporting. For this reason, I opted for a game-theoretical approach. Nevertheless, Crew and Parker's model, primarily used to study quality-of-service regulation, provides a starting point for an extended EMIR reporting model.

\section{EXTENSION TO HETEROGENEOUS FIRMS AND COMPLIANCE SUBSIDIES}

The idea of this extension is not to replicate the above analysis with more complicated functional forms. Instead, I will extend certain elements of the model, while simplifying other to gain insight into the 
general results that may come from an EMIR reporting model with heterogeneous firms and compliance subsidies.

The regulator would like to design an incentive scheme that induces firms to reveal how much they are complying with EMIR reporting requirements when the quality of reporting is hidden from the regulator. As before, we assume compliance with EMIR reporting requirements, $\alpha$, and any noncompliance fines, $f$, are the only costs to firms when trading in derivatives. To incentivise firm participation in the derivatives market, the regulator compensates the firm for any compliance costs resulting from EMIR reporting requirements. However, the regulator does not know the cost function that determines a particular compliance cost reported by a firm. If a cost $C(\alpha)$ is observed, the regulator does not know whether it is an efficient firm providing high compliance or an inefficient firm providing low compliance. The regulator presumes that the firm would like to minimise effort, and we assume the regulator knows the firm's disutility of compliance function $\psi(\alpha)$.

As in Crew and Parker's model, for mechanical reasons, we assume that the regulator prefers higher fines to lower fines. This was one of the key assumptions for the Crew and Parker model which is incompatible with EMIR reporting. As explained previously, higher fines can result in Pareto distortions. Additionally, in the UK for example, the FCA does not receive fine revenue, so they do not have budgetary motivations to issue higher fines.

As before, we assume the regulator can determine a socially-optimal target compliance level $\alpha^{*}$. We assume there are two types of firms, efficient firms that can comply with EMIR reporting requirements at a low cost and inefficient firms that incur high compliance costs. By nature, efficient and inefficient firms are endowed with cost parameters $\gamma^{\prime}$ and $\gamma^{\prime}$ respectively, where $\gamma^{\prime}<\gamma^{\prime}$. To avoid overcomplicating the problem with assumptions on the efficiency of financial firms across all business activities, in this extension of the EMIR reporting model, we introduce simplified cost functions that focus solely on the cost of EMIR reporting. Efficient and inefficient firms have cost functions $C^{\prime}(\alpha)$ and $C^{\prime \prime}(\alpha)$, respectively.

$$
\begin{aligned}
& C^{\prime}(\alpha)=\gamma^{\prime}-(1-\alpha) \\
& C^{\prime \prime}(\alpha)=\gamma^{\prime \prime}-(1-\alpha)
\end{aligned}
$$

To ensure socially-optimal compliance from both firm types, the regulator must offer two types of contracts with appropriate incentives.

We assume both firm types have the following utility function, where $t$ is a profit parameter and $\mathrm{f}$ a fine for non-compliance:

$$
U=t-\psi(\alpha)-f
$$


We assume firms make a positive profit from derivative trading without regulatory compliance costs. Therefore, they will participate in derivative trading as long as $U \geq 0$.

Based on this, the regulator offers a contract to firms with two components:

1. Engage a firm to trade in derivatives, and observe the compliance cost reported by the firm.

2. Pay the compliance cost and fine the firm for any non-compliance, i.e. $\alpha<1$.

When designing appropriate contracts for efficient and inefficient firms, the main issue for the regulator is that efficient firms should report a lower compliance cost at $\alpha^{*}$. As we assume the regulator covers this cost entirely, efficient firms may pretend to be inefficient to receive a higher compensatory payment.

It is helpful to visualise the ideal contracts graphically. From a firm's perspective, higher costs and a higher fine are both economic 'bads'. Therefore, in figure 5, utility is decreasing along both the $\mathrm{x}$ - and $\mathrm{y}$-axis and the indifferences curves are inverted.

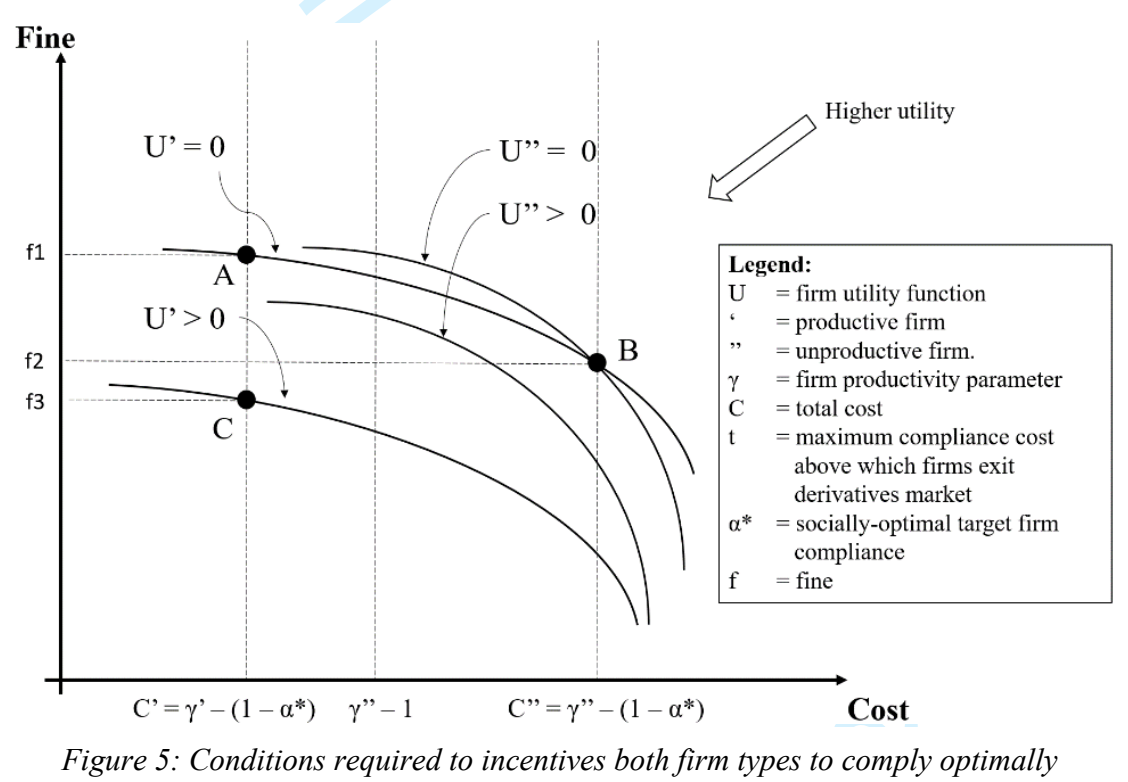

For efficient firms, a marginal fine increase is more costly relative to higher compliance compared to the inefficient firm. Therefore, the efficient firm would be more willing to trade-off higher compliance for a lower fine than the inefficient firm. For this reason, the indifference curves are flatter for efficient firms than inefficient firms.

The regulator could offer the two contracts (A, B). The efficient firm would then be indifferent between optimal and sub-optimal EMIR reporting compliance. To ensure both firms choose the contracts designed for socially-optimal compliance of their efficiency type without any further assumptions, the regulator must offer a contract to efficient firms where $U>0$. A possible set of contracts could be the two contracts $(B, C)$. The efficient firm will choose contract $C$, as it is on a lower disutility curve. The 
inefficient firm cannot choose $\mathrm{C}$ as the costs are below $\gamma$ " -1 , the costs the regulator would observe if they provided no compliance. Therefore, the inefficient firm would choose contract B.

We can also illustrate the specific conditions for a feasible set of contracts using individual rationality and incentive compatibility constraints. In this case, the individual rationality constraints ensure that the two firm types participate in derivatives trading. The incentive compatibility constraints ensure each firm type chooses the correct contract designed to incentivise socially-optimal compliance $\alpha^{*}$.

Individual rationality constraints:

$$
\begin{aligned}
U^{\prime} & \geq 0 \\
U^{\prime \prime} & \geq 0
\end{aligned}
$$

Incentive compatibility constraints:

$$
\begin{aligned}
\gamma^{\prime \prime}-1 & >\gamma^{\prime}-\left(1-\alpha^{*}\right) \\
U^{\prime}\left(C^{\prime}, f 3\right) & >U^{\prime}\left(C^{\prime}, f 1\right)
\end{aligned}
$$

Equations (18) and (19) ensure firms get non-negative utility from derivative trading. Equation (20) shows under which conditions inefficient firms would then choose the contract under which they would provide socially-optimal compliance. The left-hand side of (20) represents the cost to inefficient firms if they provide no compliance $(\alpha=0)$. If the cost of providing socially-optimal compliance for efficient firms is greater than this, inefficient firms may pretend to be an efficient firm, but offer no compliance. Equation (21) says that for the efficient firm to be incentivised to provide socially-optimal compliance, they need to gain positive utility from trading in derivatives.

There are two main takeaways from this illustrative extension to the EMIR reporting model. Firstly, with heterogeneous firms, it is even more important for the regulator to use observables metrics to infer information about unobservable characteristics of the reporting firms. It is also crucial for the regulator to be able to accurately map these observed characteristics into their expected unobservables. Secondly, it may also be necessary for the regulator to compensate firms for the costs of EMIR reporting, particularly if they want firms to provide full compliance.

Overall, the EMIR reporting model can be extended to analyse elements EMIR reporting requirements in more detail. However, extending the model to resolve all the limitations above at once would have an impact on the simplicity of the model and therefore the clarity of the results. 


\section{CONCLUSION}

EMIR was the European response to the role of OTC credit derivatives in the 2008 financial crisis. A key element of this regulatory framework is a reporting requirement for each derivative trade. Academic papers and governmental reports have documented a number of issues with EMIR reporting requirements. There is a lack of consensus in academic literature on the effectiveness of public disclosure policies. Due to a different underlying regulatory mechanism in EMIR reporting, it is unclear whether previous theoretical and empirical findings on disclosure policies can be applied to EMIR reporting. To determine the effectiveness of the design of EMIR reporting requirements, this paper presents an imperfect information model of EMIR reporting. Using the example of heterogeneous firm efficiency, I also illustrate how the EMIR reporting model can be extended to account for some of the limitations of the model based on other theoretical models in academic literature. Based on the EMIR reporting model, this paper finds that while firms are unlikely to comply fully with EMIR reporting requirements, it is possible to induce firms to a relatively high extent. As long as the firm believes that the cost of non-compliance detection is not too high for the regulator, they are incentivised to comply. Based on the theoretical models developed in this paper, EMIR reporting requirements are not fundamentally flawed. As long as the regulatory objectives are clear, firms should move towards an equilibrium of providing socially-optimal compliance, trading in the number of derivatives that balances the profits that can be made with the associated compliance costs. Although this does not mean we are immune from another financial crisis, more effective EMIR reporting requirements should equip European regulators to monitor a more transparent and secure derivatives market.

Word count: 8151 


\section{BIBLIOGRAPHY}

Allingham, M.G., Sandmo, A. (1972), "Income tax evasion: a theoretical analysis", J. Public Econ, Vol 1, pp. 323-338.

Alvarez, F., Barlevy, G. (2015), "Mandatory Disclosure and Financial Contagion ", Working Paper No. 21328, National Bureau of Economic Research, Cambridge MA 02138, July 2015.

Armstrong, M., Huck, S. (2010), "Behavioral Economics as Applied to Firms: A Primer", Compet. Policy Int. Vol. 6.

Avgouleas, E. (2009), "The Global Financial Crisis and the Disclosure Paradigm in European Financial Regulation: The Case for Reform", Eur. Co. Financ. Law Rev, Vol. 6, pp. 440-475.

Ayadi, R., Behr, P. (2009). "On the necessity to regulate credit derivatives markets". J. Bank. Regul. Vol. 10, pp. 179-201.

Becker, G.S., Landes, W.M. (1974). Essays in the economics of crime and punishment, Human behavior and social institutions, Columbia University Press, New York.

Ben-Shahar, O., Schneider, C.E. (2014), "The Futility of Cost-Benefit Analysis in Financial Disclosure Regulation", J. Leg. Stud. Vol. 43, pp. 253-271.

Bernasconi, M., (1998) "Tax evasion and orders of risk aversion", J. Public Econ, Vol. 67, pp. 123134.

Beyer, A., Cohen, D.A., Lys, T.Z., Walther, B.R. (2010), "The financial reporting environment: Review of the recent literature", J. Account. Econ, Vol. 50, pp. 296-343.

Bank for International Settlements (2019), "Statistical release: OTC derivatives statistics at end-June 2019", available at: https://www.bis.org/publ/otc_hy1911.pdf (accessed 28 August 2020).

Christensen, H.B., Hail, L., Leuz, C. (2016), "Capital-Market Effects of Securities Regulation: Prior Conditions, Implementation, and Enforcement", Rev. Financ. Stud, Vol. 29, pp. 2885-2924.

Chui, M. (2012), "Derivatives markets, products and participants: an overview", available at: https://www.bis.org/ifc/publ/ifcb35a.pdf (accessed 28 August 2020).

Claessens, S., Kodres, L. (2014), "The Regulatory Responses to the Global Financial Crisis: Some Uncomfortable Questions", working paper 14/46, International Monetary Fund, Washington D.C., March 2014.

Cohen, M.A., Santhakumar, V. (2007), "Information Disclosure as Environmental Regulation: A Theoretical Analysis", Environ. Resour. Econ, Vol. 37, pp. 599-620.

Crew, M.A., Parker, D. 2006. International Handbook on Economic Regulation, Edward Elgar Publishing, Cheltenham Gloucestershire.

Cripps, M. (2006), Reputation, The New Palgrave Dictionary of Economics, Palgrave Macmillan, London.

De Larosiere, J., Balcerowicz, L., Issing, O., Masera, R., Mc Carthy, C., Nyberg, L., Perez, J., Ruding, O. (2009), "The High-Level Group on Financial Supervision in the EU" available at: 
https://ec.europa.eu/economy_finance/publications/pages/publication14527_en.pdf (accessed 28 August 2020).

European Securities and Markets Authority (2018), "ESMA's supervision - 2018 Annual Report and 2019 Work Programme" available at: https://www.esma.europa.eu/sites/default/files/library/msp_ar2018_and_wp2019.pdf (accessed 28 August 2020).

European Commission (2017), "Report from the Commission to the European Parliament and the Council on the need to temporary exclude exchange-traded derivatives from the scope of Articles 35 and 36 of the Regulation (EU) No 600/2014 on markets in financial instruments." available at: https://ec.europa.eu/transparency/regdoc/rep/1/2017/EN/COM-2017-468-F1-ENMAIN-PART-1.PDF (accessed 28 August 2020).

European Commission (2014a), "COMMISSION IMPLEMENTING REGULATION (EU) No 1348/2014 of 17 December 2014 on data reporting implementing Article 8(2) and Article 8(6) of Regulation (EU) No 1227/2011 of the European Parliament and of the Council on wholesale energy market integrity and transparency", Off. J. Eur. Union Vol. L363, pp 121142.

European Commission (2014b), "Regulation (EU) No 600/2014 of the European Parliament and of the Council of 15 May 2014 on markets in financial instruments and amending Regulation (EU) No 648/2012", Off. J. Eur. Union, Vol. L173, pp. 84-148.

European Commission (2012), "Regulation (EU) No 648/2012 of the European Parliament and of the Council of 4 July 2012 on OTC derivatives, central counterparties and trade repositories", Off. J. Eur. Union, Vol. L201, pp. 1-59.

Financial Conduct Authority (2020), "FCA Handbook", available at: https://www.handbook.fca.org.uk/handbook (accessed 28 August 2020).

Financial Conduct Authority (2019a), "About the FCA", available at: https://www.fca.org.uk/about/the-fca (accessed 28 August 2020).

Financial Conduct Authority (2019b), "FCA Mission: Approach to Supervision", available at: https://www.fca.org.uk/publication/corporate/our-approach-supervision-final-reportfeedback-statement.pdf (accessed: 28 August 2020).

Financial Conduct Authority (2017a), "Final Notice to Merrill Lynch International", available at: https://www.fca.org.uk/publication/final-notices/merrill-lynch-international-2017.pdf (accessed 28 August 2020).

Financial Conduct Authority 2017b. Enforcement Information Guide. Financ. Conduct Auth. https://www.fca.org.uk/publication/corporate/enforcement-information-guide.pdf

Futures Industry Association (2019), "Reporting Exchange Traded Derivatives under EMIR", available at: https://fia.org/file/9024/download?token=kDyL15aT (accessed 28 August 2020). 
Financial Stability Board 2018, "Incentives to centrally clear over-the-counter (OTC) derivatives", available at: https://www.fsb.org/2018/08/incentives-to-centrally-clear-over-the-counter-otcderivatives/ (accessed 28 August 2020).

Goldstein, I., Yang, L. 2017 "Information Disclosure in Financial Markets" Annu. Rev. Financ. Econ, Vol. 9, pp. 101-125.

Gordon, J.P.P. (1989), "Individual morality and reputation costs as deterrents to tax evasion", Eur. Econ. Rev, Vol. 33, pp. 797-805.

Guttentag, M.D. (2007), "Accuracy Enhancement, Agency Costs, and Disclosure Regulation", Rev. Law Econ, Vol. 3, pp. 611-641.

Hail, L., Leuz, C. (2006), "International Differences in the Cost of Equity Capital: Do Legal Institutions and Securities Regulation Matter?" J. Account. Res, Vol. 44, pp. 485-531.

Hermalin, B.E., Weisbach, M.S. (2012), "Information Disclosure and Corporate Governance" J. Finance, Vol. 67, pp. 195-233.

Kanto, A.J., Schadewitz, H.J. (1997), "A multidimensional model for the disclosure policy of a firm", Scand. J. Manag, Vol. 13, pp. 229-249.

Kiser, E. (2004), "Modeling the Whole Firm: The Effect of Multiple Inputs and Financial Intermediation on Bank Deposit Rates", working paper [No. 2004-07, 46], Federal Reserve Board, Washington D.C, 11 March 2004.

Lehmus, M. (2011), "Labor or consumption taxes? An application with a dynamic general equilibrium model with heterogeneous agents", Econ. Model, Vol. 28, pp. 1984-1992.

Leuz, C., Wysocki, P.D. (2016), "The Economics of Disclosure and Financial Reporting Regulation: Evidence and Suggestions for Future Research", J. Account. Res, Vol. 54, pp. 525-622.

Levine, A.M., Macey, J.C. (2017), "Dodd-Frank Is a Pigouvian Regulation", Note. Yale Law J, Vol. 127, pp. 1336-1415.

Liu, L., Ondrich, J., Ruggerio, J. (2012), "Estimating Multiple-Input--Multiple-Output Production Functions with an Analysis of Credit Unions", Appl. Econ, Vol. 44, pp. 1583-1589.

Mitchell, R.B. (2011), "Transparency for Governance: The Mechanisms and Effectiveness of Disclosure-Based and Education-Based Transparency Policies", Ecol. Econ, Vol. 70, pp. $1882-1890$.

Osborne, M.J. (2009), An Introduction to Game Theory, Oxford University Press, Oxford.

Pemberton, M., Rau, N. (2015), Mathematics for Economists: An Introductory Textbook, Manchester University Press, Manchester.

Pérez-Duarte, S., Skrzypczynski, G. (2018), "Two is company, three's a crowd: automated pairing and matching of two-sided reporting in EMIR derivatives' data", available at: https://www.bis.org/ifc/publ/ifcb49_51.pdf (accessed 28 August 2020).

Porta, R.L., Lopez-De-Silanes, F., Shleifer, A. (2006), "What Works in Securities Laws?" J. Finance Vol. 61, pp. 
Reiter, M. (2009), "Solving heterogeneous-agent models by projection and perturbation", J. Econ. Dyn. Control, Vol. 33, pp. 649-665.

Rousová, L.F., Osiewicz, M., Skrzypczyński, G. (2015), "The challenges of standardisation and aggregation of EMIR data in Europe: six trade repositories and 28 countries", available at: https://www.bis.org/ifc/events/ifc_isi_2015/089_rousova_osiewicz_skrzypczynski_paper.pdf (accessed 28 August 2020).

Sappington, D.E.M., Sibley, D.S. (1988), "Regulating without Cost Information: The Incremental Surplus Subsidy Scheme", Int. Econ. Rev, Vol. 29, pp. 297-306.

Shen, W. (2011), "Is It All about Disclosure? Regulating Structured Financial Products after the Lehman Brothers Minibonds Saga", Wong, M.C.S. (Ed.), The Risk of Investment Products: From Product Innovation to Risk Compliance, World Scientific Publishing, Hackensack, N.J. and Singapore, pp. 41-78.

Tversky, A., Kahneman, D. (1974). "Judgment under Uncertainty: Heuristics and Biases", Science Vol. 185, pp. 1124-1131.

van Lelyveld, I. (2017), "The use of derivatives trade repository data: possibilities and challenges", available at: https://www.bis.org/ifc/publ/ifcb46z.pdf (accessed 28 August 2020).

Weil, D., Fung, A., Graham, M., Fagotto, E. (2006), "The Effectiveness of Regulatory Disclosure Policies", J. Policy Anal. Manage, Vol. 25, pp. 155-181.

Wilkes (2019), "Pairing and matching rates EMIR - a Freedom of Information request to European Securities and Markets Authority", available at: https://www.asktheeu.org/en/request/pairing_and_matching_rates_emir (accessed 28 August 2020).

World Bank (2019), GDP (current US\$), World Bank, available at: https://data.worldbank.org/indicator/NY.GDP.MKTP.CD (accessed 28 August 2020).

Xepapadeas, A.P. (1991), "Environmental policy under imperfect information: Incentives and moral hazard", J. Environ. Econ. Manag, Vol. 20, pp. 113-126.

Yitzhaki, S. (1974), "Income tax evasion: A theoretical analysis", J. Public Econ, Vol. 3, pp. 201202. 